\title{
Benefícios sociais da política de incentivos à cultura de mamão no Estado do Ceará
}

\author{
Heliana Mary da Silva Quintino ${ }^{1}$ \\ Ahmad Saeed Khan ${ }^{2}$ \\ Patrícia Verônica Pinheiro Sales Lima ${ }^{3}$
}

Resumo: Este estudo analisa o benefício social gerado pelos incentivos governamentais do Ceará aos produtores de mamão do estado, no período de 2001 a 2006, considerando como base teórica uma abordagem do excedente econômico de Marshall e os modelos de equações simultâneas. Os resultados apontaram que a oferta de mamão no Ceará tem elasticidade-preço alta. Entretanto, apesar do comportamento decrescente dos preços, houve aumento médio significativo da oferta. A redução nos preços e o paralelo aumento na oferta foram responsáveis por uma elevação no bem-estar social da população. O excedente econômico totalizou um valor agregado de $\mathrm{R} \$ 3.163 .045,00$ e per capita de $\mathrm{R} \$ 0,39$. Isto revela a importância de ações voltadas para a redução nos custos de produção como forma de estimular o desenvolvimento da fruticultura no estado. $O$ benefício social por meio da geração de empregos totalizou $\mathrm{R} \$ 4.690 .041,00$, sendo $\mathrm{R} \$ 2.814 .025,00$ correspondentes a empregos indiretos, e $\mathrm{R} \$ 1.876 .016,00$ a empregos diretos. Os produtores perceberam um incremento em suas receitas médias per capitas de $167,05 \%$ e agregadas, de $282,74 \%$. Conclui-se que os diversos programas de fomento à fruticultura projetaram o mercado de mamão cearense, gerando uma tendência crescente da produção e número de empregos.

Palavras-chave: Excedente econômico de Marshall; equações simultâneas; fruticultura.

\footnotetext{
${ }^{1}$ Mestre em Economia Rural, Professora da Universidade Federal do Piauí. E-mail: iana_quintino@yahoo.com.br

${ }^{2}$ Eng. Agrônomo Ph.D. Prof Titular do Depto de Economia Agrícola da Universidade Federal do Ceará. E-mail: saeed@ufc.br

${ }^{3}$ Doutora em Economia. Professora do Departamento de Economia Agrícola da Universidade Federal do Ceará. Bolsista CNPq. E-mail: pvpslima@ufc.br
} 


\begin{abstract}
This study analyzes social benefits created by Ceará government incentives to papaya producers from 2001 to 2006. As theoretical basis, it was considered an approach of the economic surplus of Marshall and simultaneous equations model. Results indicate that the supply price-elasticity of papaya is very high. In spite of the decrease in quotes, there was a boost in the average amount supplied. The reduction in prices and increases in quantity are responsible for the rise in the society welfare. The aggregate value of total and per capita social benefits were of 3,163,045.00 reais and 39 cents of real, respectively. It shows the importance of actions taken by the government to reduce the cost of production in order to stimulate the development of fruit crops at Ceara state. The total social benefits of 4,690,042.00 reais were obtained by creating direct job opportunities of 1,876,016.00 reais and indirect employments of 2,814,025.00 reais. The producers received a boost in their average per capita income and total revenue of 167.05 percent and 282.74 percent, respectively. As a result, it is possible to conclude that many programs related to promote fruit production in Ceará have showed a boosting trend in production of papaya and in number of employments created.
\end{abstract}

Key-words: Economic surplus of Marshall; simultaneous equations; fruit crop.

Classificação JEL: Q 180.

\title{
1. Introdução
}

A importância das políticas públicas para o desenvolvimento do setor agrícola é revelada através do desempenho dos diversos mercados de produtos derivados desse setor. Neste sentido, o comportamento da oferta, demanda e preços de mercado funcionam como indicadores dos efeitos multiplicadores das políticas implementadas.

Basicamente, as diretrizes das intervenções governamentais na agricultura visam à dotação de mecanização, investimentos, irrigação, treinamento, assistência técnica e financeira por meio de crédito dos bancos oficiais aos produtores. Essas iniciativas aplicadas com eficácia e eficiência viabilizam a cadeia produtiva e agregam valor ao produto, fomentando a capacidade competitiva, possibilitando ao setor fazer frente ao cenário mercadológico mundial, além de promover a ampliação de bem-estar para o contexto da sociedade.

No estado do Ceará, o setor agrícola é um promotor do desenvolvimento econômico rural, principalmente no que se refere à geração de renda. A agricultura ocupa $30,8 \%$ da população economicamente ativa. O setor da agricultura e da agroindústria representa $71 \%$ das exportações cearenses e $20 \%$ do PIB Estadual (SDE, 2006, p. 39). 
Entretanto, a produção agrícola tradicional é de alto risco, baixo nível técnico, pouco produtiva e predominantemente de subsistência, dependente de chuvas que geralmente são irregulares. Grande parte da produção é realizada por pequenos produtores, de um modo geral, mais vulneráveis aos riscos. Além disso, de acordo com o Instituto de Pesquisa e Estratégia Econômica do Ceará (IPECE), 93\% do território cearense localiza-se na região semiárida do Nordeste. Em geral, seus solos apresentam-se com pouca profundidade, deficiências hídricas, pedregosidade e, principalmente, susceptíveis à erosão.

Neste contexto, a articulação de ações para melhorar a estrutura produtiva, a competitividade, para garantir a sustentabilidade do abastecimento e o aproveitamento de potencialidades locais, justifica a implementação de políticas governamentais. Observa-se que há alguns anos, investimentos públicos, federais e estaduais, vêm sendo implementados neste sentido no Ceará (SDE, 2006, p. 7).

Como consequência dessas políticas, a fruticultura vem se destacando no cenário econômico cearense, contribuindo sobremaneira para o PIB e integração comercial do Estado. $\mathrm{O}$ respaldo dessa atividade está essencialmente na geração de emprego e renda em regiões historicamente castigadas pela falta desses recursos. Dados de Seagri (2005) apontam que, em 2004, as atividades com a fruticultura empregaram 44.312 trabalhadores, sendo 17.771 empregos diretos. Em 2005, os empregos diretos expandiram-se em 19,16\%, subindo para 21.177. A área cultivada passou de 18.044 hectares em 1999 para 37.761 em 2005, ampliando em 19.717 hectares a área plantada de frutas. Em 2006, área plantada alcançou 43.226 hectares.

Para a viabilização da cadeia produtiva de frutas, o Estado elegeu o estímulo ao cultivo de seis frutas, consideradas de maior potencial em termos de agricultura irrigada e competitividade: abacaxi, banana, mamão, manga, melão e uva. Dessas seis frutas beneficiadas, a banana, o melão e o mamão despontam, nessa ordem, com os melhores indicadores de área irrigada, produção e emprego em 2004.

Entretanto, em termos de comercialização, verifica-se que no mesmo ano, os maiores indicadores de exportação são, em ordem, o melão e o abacaxi, ficando o mamão em último lugar no ranking, o que caracteriza que a maior parcela da produção cearense de mamão é voltada para o abastecimento do mercado interno, cerca de 98,5\% ${ }^{4}$. Conforme Barreto et al. (2002, p. 8), 99,5\% do consumo é atendido pela produção do estado. É válido ressaltar que, consideranto as exportações totais de frutas do Ceará, parte destas é composta pela produção de outros estados.

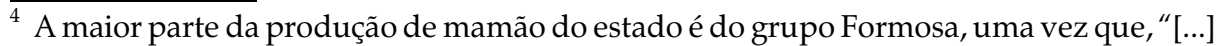
nas condições locais, os genótipos do grupo Solo (havaí/papaya) manifestam deficiências importantes como a esterilidade de verão, carpeloidia e baixa produtiviade (BARRETO et al., (a), 2002, p. 8).
} 
De acordo com o Agrianual, ano de 2005, o Ceará é o quarto maior produtor nacional de mamão. Segundo Seagri (2006) o estado teve, em 2005, uma área colhida de 1.498 hectares e uma produção de 63.276 toneladas. Em contrapartida, em 2000, a área colhida havia sido de 1.182 hectares e a produção, de 39.428 toneladas, o que revela a contribuição positiva das ações de investimentos voltadas à irrigação neste período.

Consideram-se, aqui, as hipóteses de que implementar medidas de promoção do desenvolvimento da agricultura significa, sobretudo, promover a ampliação de bem-estar desde o meio rural até os centros urbanos; e que o estímulo implementado no setor primário, em geral, é transferido à sociedade.

Diante disto, a proposta do presente estudo foi promover uma análise do benefício social das políticas de incentivo aos produtores de mamão do Ceará no período 2001-2006. Especificamente, estimou-se o benefício social bruto agregado e per capita gerado pela política de incentivo aos produtores de mamãoe os benefícios sociais brutos associados à geração de empregos.

Esta análise se justifica uma vez que a investigação dos efeitos sociais das ações estratégicas se materializa como uma fonte de informação pública, bem como um apoio suplementar ao esforço de avaliação do desempenho da atuação política no setor de fruticultura.

\section{Políticas públicas voltadas à fruticultura}

Nesta seção, são apresentadas as principais iniciativas federais e estaduais voltadas para o desenvolvimento da fruticultura e, consequentemente, do mamão, no estado do Ceará e cujos benefícios são avaliados neste estudo.

\subsection{Políticas públicas federais e estaduais para o desenvolvimento da fruticultura}

O Nordeste tem papel relevante no desempenho da fruticultura do Brasil. Concomitantemente, a fruticultura é uma atividade intensa que contribui, sobremaneira, para a economia da região. As frutas tropicais são principalmente produzidas nas áreas semiáridas, abrindo uma possibilidade de desenvolvimento para estas economias historicamente fragilizadas. A relevância do estímulo a esse setor produtivo é a possibilidade de absorção de mão de obra e geração de emprego e renda nessas regiões. Nesses particulares, o apoio governamental representa um papel crucial com iniciativas de incentivo à fruticultura irrigada, tendo em vista as vantagens comparativas locais de disponibilidade de mão de obra, clima, localização em relação aos principais mercados consumidores. 
O incentivo governamental à fruticultura brasileira se baseia em estratégias de apoio à produção, por meio de sistemas de crédito ao produtor e da modernização dos serviços gerais, comercialização e das atividades inerentes à fruticultura. Os objetivos básicos são o incremento da infraestrutura do setor e o fomento à competitividade. Com estes propósitos foram adotadas medidas como:

1. o Programa de Apoio e Desenvolvimento da Fruticultura Irrigada do Nordeste (1997). Foi implementado com o objetivo de promover a inserção competitiva do Brasil no mercado internacional de frutas frescas, através do estímulo desta atividade nas regiões semiáridas dos estados nordestinos. Esta estratégia contribuiu, sobretudo, para a geração de emprego e renda nestas áreas;

2. a Companhia Nordestina de Frutas foi criada com o objetivo de ampliar a movimentação financeira para este setor da economia regional através, principalmente, da captação de recursos federais e estaduais para a promoção de investimentos em infraestrutura e a consequente expansão da fruticultura no semiárido;

3. o Programa de Desenvolvimento da Fruticultura (Prodefruta) - Resolução CMN/ BACEN no 3.095, de 25/06/2003 -, tem como finalidade conceder crédito aos produtores de fruta do País inseridos no programa de crédito rural, em todo território nacional. Este programa passou a abranger os programas originalmente lançados como Programa de Desenvolvimento da Vitivinicultura (Prodevinho), Programa de Apoio ao Desenvolvimento da Cacauicultura (Procacau), Programa de Desenvolvimento da Cajucultura (Procaju) e Programa de Apoio à Fruticultura (Profruta). O maior objetivo do Prodefruta é promover a produção de espécies de frutas com potenciais mercadológicos interno e externo;

4. o Programa de Desenvolvimento da Fruticultura (Profruta) é um programa estruturante e uma das estratégias prioritárias do Ministério da Agricultura, Pecuária e Abastecimento (Mapa). O objetivo do Profruta é a consolidação dos padrões de qualidade e competitividade da fruticultura brasileira, mediante as exigências internacionais de mercado. Este Programa é composto de diversas estratégias voltadas para o atendimento dos diversos segmentos da fruticultura brasileira;

5. a Produção Integrada de Frutas (PIF) é uma estratégia europeia da década de 1980, articulada no Brasil a partir de 1998. O objetivo da PIF é desenvolver métodos, processos, normas, sanções e metodologias de manejo da produção integrada de frutas no Brasil, respeitando as normas estabelecidas internacionalmente pela Organização Internacional de Controle Biológico (OILB), com vistas à obtenção de padrões de produção ambientalmente corretos e ao aumento da competitividade internacional e da qualidade das frutas brasileiras. 
6. a estratégia de Desenvolvimento, Produção, Distribuição de Material Propagativo de Fruteiras, Organização e Capacitação de Viveiristas, tem como objetivos a criação e manutenção de pomares e de fruteiras como fonte de material genético de micropropagação e macropropagação; produção de mudas para e com associações de viveiristas estrategicamente selecionados; criação de uma infraestrutura mínima de reprodução macro e micropropagada; treinamento de viveiristas em ações técnicas e comerciais; facilitação do atendimento da demanda por meio da execução de ações tecnológicas nas próprias regiões.

No Ceará, em coexistência com as estratégias citadas, podem ser citadas iniciativas como o Projeto de Frutas do Ceará cujo objetivo principal é a intensificação da produção de frutas com potencial competitivo (abacaxi, banana, mamão, melão, manga e uva). Os investimentos do Projeto Frutas do Ceará baseiam-se em ações de apóio técnico na formação de sistema de certificação de frutas para exportação; delimitação e manutenção da área livre de moscas das frutas. Essas estratégias estimularam a ampliação da produção, a área irrigada para o cultivo de frutas, a demanda do setor por mão de obra e as exportações.

O fortalecimento do setor de frutas do Ceará foi reforçado, também, com estratégias de investimento em infraestrutura como:

1. os canais de abastecimento de água Castanhão e o Canal da Integração que ampliaram em $40 \%$ a disponibilidade de água para a agricultura irrigada;

2. a criação do Instituto Agropólos do Ceará, em 2002, como uma instituição de caráter privado, qualificado para prestação de serviços, através de contrato de gestão, em que foram zoneadas as regiões com maiores potencialidades para a agricultura irrigada;

3. os projetos de irrigação estruturados pelo DNOCS (Departamento Nacional de Obras Contra as Secas) em parceria com o governo do estado;

4. os portos de Mucuripe e Pecém localizados a cerca de $350 \mathrm{~km}$ das principais áreas produtoras - o Porto do Pecém é atualmente o maior porto exportador de frutas do País, tem uma estrutura moderna, com capacidade para receber navios de grande calado;

5. o Centro de Formação Tecnológica (Centec), com 43 unidades espalhadas pelo interior do estado, formando profissionais e prestando serviços aos produtores e exportadores. Segundo SDE (2006), a Política de Desenvolvimento do Agronegócio é apoiada, dentre outras, pelas ações de Promoção do Agronegócio da Agricultura Irrigada, Desenvolvimento Agroindustrial e de Atração de Investimento na fruticultura competitiva. 
Por fim, merece menção a Política Seletiva de Atração de Investimentos (Fundo de Desenvolvimento Industrial - FDI $)^{5}$ que contempla diversos segmentos. No setor rural, o segmento produtivo industrial da agroindústria é privilegiado pelas ações dessa estratégia, que são: financiamento de equipamentos de irrigação, embalagens de vidro a vácuo, de polietileno e PET, instalação de irrigação, instalação de tratamento hidrotérmico, casas de vegetação (mudas, rosas, cultivos protegidos, secagem de frutas, desidratação), defensivos orgânicos, tratores e implementos (pulverizadores, plantadeiras mecânicas, grade mecânica, etc.), sementes e mudas, câmaras frias e de climatização (frutas e hortaliças), equipamentos para a indústria de alimentos (equipamentos de concentração, envase, extração, estufas, aço inox) e insumos para fabricação de alimentos, como aditivos (corantes, conservantes, espessantes).

\subsection{O Desenvolvimento da fruticultura do Ceará pós-política de frutas}

Segundo a Seagri (2006), como consequência das políticas implementadas, houve incrementos na geração de emprego e renda em regiões historicamente castigadas pela falta desses recursos. Este estudo considera o ano de 2001 como o ano de referência do período ex post ao Projeto Frutas do Ceará. Assim, em 2005, segundo Ximenes (2006), o cultivo de frutas ocupava uma área superior a 29 mil hectares, um aumento de cerca de $58 \%$ desde 2000 . Em termos de produção, no mesmo período, o aumento foi de $85 \%$ - passou de 484 mil para 896 mil toneladas. Projetou-se para 2006, um crescimento de $22 \%$. O valor bruto da produção em 2005 cresceu 259,8\% nos últimos seis anos, saltou de R 92.510 milhões em 1999 para R\$ 332.860 milhões em 2005. Para 2006, projetou-se o valor de R 474.469 milhões.

O maior destaque da fruticultura do estado se dá em termos de exportação. Em 2005, o Ceará foi o quinto maior exportador de frutas do País e o quarto maior do Nordeste. Na balança comercial cearense, a fruticultura foi o item que mais cresceu relativamente aos demais itens exportados, com um acréscimo de 79,7\%.

No que diz respeito ao mamão, o Brasil ocupa a primeira posição na produção mundial desta fruta há pelo menos 10 anos. A produção brasileira do mamão acontece em todos os estados do território, entretanto, o volume produzido concentra-se na região Nordeste do País. No Nordeste, os principais estados produtores são, por ordem, a Bahia, com 783.600 toneladas em 2002 e 16.930 hectares de área colhida, a Paraíba, com 65.253 toneladas e 1.394 hectares, e o Ceará, com 53.744 toneladas e 1.693 hectares.

\footnotetext{
${ }^{5}$ Detalhamento extraído de Política de Desenvolvimento Econômico. Governo do Ceará, 2004, p. 55-70.
} 
O Ceará é o terceiro maior produtor de mamão do Nordeste e o quarto do Brasil. A cultura do mamão ocupou, em 2004, uma área total de 1.691 ha, dos quais 1.008 ha correspondem a áreas irrigadas. Assim, o mamão, sozinho, representa $3,64 \%$ de toda área irrigada do setor de frutas do estado. A cultura do mamão gerou 2.120 mil empregos em 2004. Deste total, 848 corresponderam a empregos diretos. Desde os incentivos à fruticultura, a produção estadual aumentou $57,12 \%$ de 1999 para 2006, passando de 40.271 para 63.276 toneladas, respectivamente, o que trouxe benefícios sociais à população.

\section{Aspectos teóricos da análise de benefício social total (BST)}

Com frequência, uma abordagem de avaliação de benefício social é feita, basicamente, por meio da análise de excedente econômico gerado pela implementação ou não de um determinado projeto (CRUZ, 1982 apud SOUSA, 1988).

As principais premissas presentes no conceito de excedente econômico de Marshall dizem que a área total sob a curva de demanda à esquerda de uma dada quantidade representa a utilidade total desta quantidade e que a curva de oferta reflete os custos de oportunidade dos recursos variáveis utilizados para produzir cada quantidade.

Sob a ótica da abordagem do "excedente econômico de Marshall", alguns autores basearam seus estudos, buscando adaptá-los, de uma forma ou de outra, aos seus interesses de pesquisa. Na literatura internacional é possível citar vários autores: Griliches (1958) estimou os benefícios para a sociedade com a descoberta do milho híbrido. A sua análise considerou um deslocamento paralelo e para baixo da curva de oferta, bem como, estimativas de retornos para uma oferta perfeitamente elástica e para uma oferta perfeitamente inelástica. A demanda foi considerada com elasticidade unitária.

Peterson (1967) analisou o retorno social bruto da pesquisa com aves. Adotou as curvas de oferta e demanda tradicionais, considerando para a curva de oferta um deslocamento proporcional.

Schmitz e Seckler (1970) avaliaram os ganhos comerciais da agricultura mecanizada para o caso da colhedeira de tomate. Utilizaram curvas de demanda e oferta lineares e um deslocamento paralelo da oferta.

Akino e Hayami (1975) estimaram os benefícios sociais da pesquisa em melhoramento de arroz no Japão. Consideraram curvas de demanda e oferta com elasticidades constantes e um deslocamento pivotal da curva de oferta. Consideraram, ainda, os efeitos da política de importação de arroz.

Hertford e Schmitz (1977) avaliaram um modelo semelhante ao de Peterson. No entanto, admitiram serem lineares a demanda e a oferta, analisando um deslocamento paralelo para esta última. 
Hayami e Herdt (1978) estimaram os benefícios sociais da pesquisa do arroz nas Filipinas. Admitiram curvas de demanda e oferta com elasticidades constantes e um deslocamento pivotal da oferta. Estes autores consideraram no modelo o autoconsumo dos produtores.

Lindner e Jarrett (1978) observaram uma análise de benefícios sociais em termos do deslocamento da curva de oferta para estimar o excedente econômico decorrente de uma inovação tecnológica na agricultura. Consideraram quatro formas de deslocamento da curva: convergente, paralelo, divergente pivotal e divergente proporcional. Demonstraram que os benefícios sociais são influenciados pela natureza do deslocamento da curva de oferta.

Rose (1980) observou que os benefícios brutos de pesquisa encontrados por Lindner e Jarrett (1978) tiveram seus valores subestimados. A autora sugeriu equações alternativas para a obtenção dos preços e quantidades futuras.

Na literatura brasileira, vários estudos baseados no modelo de Lindner e Jarrett (1978) foram realizados para calcular os benefícios sociais. Dentre eles, pode-se destacar: Ayer e Schuh (1974), que estimaram os impactos econômicos dos investimentos empregados na pesquisa de algodão no estado de São Paulo. Abordaram curvas de oferta e demanda não lineares e um deslocamento pivotal da oferta.

Monteiro (1975) avaliou a pesquisa e extensão agrícola na cultura do cacau brasileiro no período de 1923 a 1975. Estimou somente o excedente do produtor, uma vez que o cacau é um produto essencialmente de exportação e, portanto, o excedente do consumidor se dá em nível externo.

Fonseca (1976) estimou o benefício social dos investimentos em pesquisa cafeeira no estado de São Paulo no período de 1930 e 1970 . Utilizou-se de procedimentos tradicionais de cálculos do excedente econômico.

Santana (1987) estimou os retornos sociais gerados com a adoção tecnológica na cultura do feijão caupi no Nordeste. Considerou curvas de oferta e demanda lineares com base no modelo de Lindner \& Jarreta (1978) e um deslocamento divergente-proporcional da curva de oferta.

Khan e Souza (1991) avaliaram os impactos sócio-econômicos dos investimentos em pesquisa na cultura de mandioca no Nordeste, considerando o autoconsumo do produto. Utilizaram o modelo de Lindner \& Jarrett(1978), com curvas de oferta e demanda lineares, considerando um deslocamento divergente-proporcional da curva de oferta.

Santana e Khan (1992) avaliaram os efeitos do desflorestamento da região produtora de castanha no estado do Pará. Estimaram os custos sociais impostos por esse desflorestamento. Concluíram que a parcela maior do custo foi a dos consumidores e que o desflorestamento levou esta atividade à exaustão.

Ferreira (1993) estimou o benefício social dos investimentos em pesquisa e assistência técnica na cultura cafeeira no estado de Minas Gerais nas décadas de 1970 e 1980. Utilizou-se dos conceitos de excedente do consumidor e do produtor. 
Silva e Khan (1994) avaliaram os impactos sociais da substituição de milho pela raspa de mandioca em ração suína no estado do Ceará. Utilizou-se do modelo de Lindner e Jarrett modificado por Rose (1980), o qual supõe curvas lineares de demanda e oferta. Os autores admitiram deslocamentos proporcional, paralelo e convergente da curva de oferta.

Bacha (1995) analisou o benefício social dos incentivos fiscais à atividade de reflorestamento no Brasil. Desenvolveu um modelo de cálculo com base no modelo de Santana e Khan (1992). Considerou deslocamentos pivotal e paralelo da curva de oferta. Constatou que os custos envolvidos com os incentivos superaram o benefício social.

Abdallah e Bacha (1999) analisaram o benefício/custo do programa de incentivos fiscais à atividade pesqueira no Brasil. Admitiram o modelo de Rose (1980) com deslocamentos pivotal e paralelo da curva de oferta. Contataram que os benefícios sociais superaram os custos incorridos no programa em questão.

Neste estudo foi utilizado o modelo de Rose, levando em consideração curvas de oferta e demanda lineares e deslocamentos paralelo e pivotal da curva de oferta para estimar o benefício social dos incentivos governamentais aos produtores de mamão do estado do Ceará.

\section{Metodologia}

\section{1. Área de estudo e fonte dos dados}

O estudo foi realizado no estado do Ceará que, segundo Ipece (2004) ocupa $1,74 \%$ do território nacional e 9,57\% de toda a extensão da Região Nordeste com uma superfície de $148.825 \mathrm{~km}^{2}$. Cerca de $93 \%$ do total de sua superfície está localizada na zona semiárida do Nordeste, onde a ocorrência de chuvas é bastante concentrada e irregular.

Para a concepção de seus objetivos, o presente estudo utilizou uma série histórica de dados anuais secundários, considerados para o período de 1973 a 2006. As informações sobre as variáveis foram obtidas na Secretaria de Desenvolvimento Agrário (SDA), no site do Instituto de Pesquisa Econômica e Aplicada, Sistema Ipeadata (2006), e na Fundação Instituto Brasileiro de Geografia e Estatística (IBGE). Os valores nominais do PIB per capita e dos preços dos produtos foram corrigidos pelo índice do IGP-DI FGV, a preços de mercado de abril de 2006.

A definição e operacionalização das variáveis utilizadas no modelo são descritas como se segue:

a) As séries das variáveis quantidade demandada e de ofertada de mamão $\left(Q_{t}^{D}\right.$ e $\left.Q_{t}^{S}\right)$ foram consideradas a partir de seus valores agregados de produção no Ceará uma vez que quase a totalidade destas referem-se ao mercado estadual (cerca de 98,5\% em 2006). Não houve, assim, preocupação com a 
dedução dos montantes exportados, sendo os mesmos inexistentes ou irrisórios durante o período analisado.

b) A série da variável preço do mamão $\left(P_{t}\right)$ foi construída a partir da média ponderada dos preços e quantidades das variedades de mamões produzidas e comercializadas no estado (papaya e formosa).

As séries das variáveis preço do abacaxi $\left(P A_{t}\right)$ e preço do melão $\left(P M L_{t}\right)$ foram construídas a partir da média ponderada dos preços e quantidades das respectivas variedades produzidas e comercializadas no estado. Para as análises das elasticidades cruzadas, o critério da inclusão do preço do abacaxi na função de demanda foi a sua composição de nutrientes semelhante a do mamão: rico em vitamina $A, B, C$, cálcio, magnésio, potássio, além de auxiliar na digestão.

Já a inclusão do preço do melão na função de oferta teve como pré-requisitos: (i) a proficuidade de rotação de culturas, considerando que "a alternância de cultivos em uma mesma área apresenta diversas vantagens em relação à monocultura, além de ser uma estratégia para o manejo integrado de pragas, doenças e plantas invasoras e utilização mais adequada dos agrotóxicos e dos nutrientes" (EMBRAPA, 2006, p. 7); (ii) o melão é uma das seis frutas que compõe a prioridade do Projeto Frutas do Ceará. (iii) há uma relativa equivalência entre as tecnologias das duas culturas ${ }^{6}$.

c) A variável PIB per capita do Ceará foi construída a partir de dados do PIB agregado e da população residente no estado para servir como variável proxy da renda $\left(R D_{t}\right)$ dos consumidores de mamão.

d) A variável dummy $\left(D_{t}\right)$ foi construída considerando zero para os anos ex ante aos incentivos do governo à fruticultura do Ceará e um para os anos ex post aos incentivos aludidos a partir de 2001.

e) A variável salário mínimo $\left(S M_{t}\right)$ foi constituída anualmente a partir das médias aritméticas simples de seus valores mensais. Foi considerada na estimação da equação de oferta como variável proxy do custo da produção de mamão.

\footnotetext{
${ }^{6}$ A faixa de temperatura para vegetação está com média anual em torno de $25^{\circ} \mathrm{C}$; sob altas temperaturas o meloeiro possibilita, ao longo do ano, duas a três safras. O ideal anual de chuvas está em $1.200 \mathrm{~mm}$, bem distribuídas ao longo do ano; déficit hídrico deve ser corrigido com irrigação artificial. Adapta-se a solo de textura média, com pH entre 6,0 a 7,5 . Tem uma produtividade média de 30t/ha e sua colheita inicia-se entre 60 e 65 dias após o plantio. Para o mamão, a faixa de temperatura para vegetação está com média anual em torno de $25^{\circ} \mathrm{C}$; é encontrado durante todo o ano. O ideal anual de chuvas está em $1.200 \mathrm{~mm}$, bem distribuídas ao longo do ano; déficit hídrico deve ser corrigido com irrigação artificial. Adapta-se a solo de textura média, com pH entre 5,5 a 6,5. Tem uma produtividade média de 34t/ha e sua colheita inicia-se entre 10 e 15 meses após o plantio.
} 


\subsection{Métodos de análise}

\subsubsection{Análise do benefício social}

Considerando o modelo de ROSE (1980), o benefício social resultante de um deslocamento da curva de oferta pode ser medido através do cálculo das áreas geométricas da Figura 1.

Figura 1. Deslocamento da curva de oferta e análise geométrica do benefício social

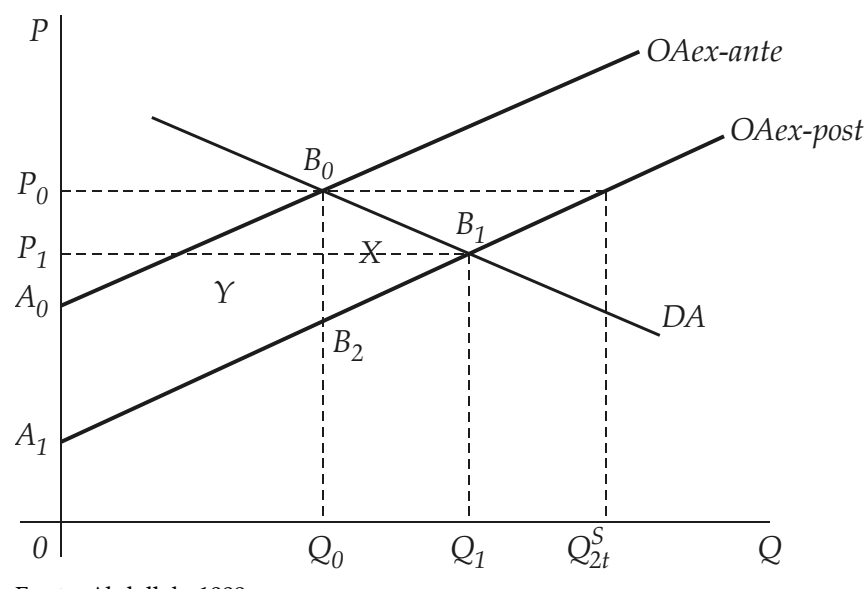

Fonte: Abdallah, 1998.

De acordo com Rose (1980, apud Abdallah e Bacha, 1999, p. 118), o aumento do excedente econômico será medido somando $B_{0} B_{1} B_{2} B_{0}(X)$ com $A_{0} B_{0} B_{2} A_{1} A_{0}(Y)$. A partir do valor da mudança no custo unitário resultante do deslocamento da oferta, dado por $B_{0} B_{2}$, o benefício social é dado por:

$$
B S T=X+Y
$$

Para o cálculo das áreas de $X$ e $Y$, toma-se o ponto de coordenadas $\left(Q_{2 t}^{S}, P_{0}\right)$ na Figura (1) e estima-se a elasticidade-preço da oferta $\left(\varepsilon^{S}\right)$ :

$$
\varepsilon^{S}=\frac{\frac{Q_{2 t}^{S}-Q_{0}}{Q_{2 t}^{S}}}{\frac{\overline{B_{0} B_{2}}}{P_{0}}}
$$


Considerando o deslocamento da curva de oferta como sendo a mudança proporcional do custo unitário, $K^{7}$ :

$$
K=\frac{\overline{B_{0} B_{2}}}{P_{0}}
$$

Substituindo equação (3) na equação (2), tem-se:

$$
\varepsilon^{S}=\frac{1-\frac{Q_{0}}{Q_{2 t}^{S}}}{K} \quad \therefore \quad K=\frac{1-\frac{Q_{0}}{Q_{2 t}^{S}}}{\varepsilon^{S}}
$$

Da equação (3), tem-se:

$$
K P_{0}=\overline{B_{0} B_{2}}
$$

A partir disto, deriva-se as equações das áreas de $X$ e $Y$ e, portanto, a equação do benefício social total (BST).

A área de $\mathrm{Y}$ foi derivada tomando-se a área do retângulo

$$
Y=Q_{0}\left(P_{0}-A_{1}\right)-0,5 Q_{0}\left(P_{0}-A_{0}\right)-0,5 Q_{0}\left(B_{2}-A_{1}\right)
$$

Denominando-se $\overline{B_{0} B_{2}}=H \therefore H=P_{0}-B_{2}$ e $B_{2}=P_{0}-H$. Substituindo $B_{2}$ e $H$ na expressão algébrica da área de $Y$ tem-se:

$$
Y=0,5 Q_{0}\left(K P_{0}+A_{0}-A_{1}\right)
$$

A partir da Figura 1 verifica-se que a área de $X$ pode ser representada pela área geométrica do triângulo com base dada pelo segmento $\overline{B_{0} B_{2}}=K P_{0}$ e sua altura dada por $\left(Q_{1}-Q_{0}\right)$.

Assim, a expressão algébrica da área de $X$ é dada por:

$$
X=0,5 K P_{0}\left(Q_{1}-Q_{0}\right)
$$

\subsubsection{Benefício social total para um deslocamento} paralelo e pivotal da curva de oferta

Neste caso, a mudança da origem influencia a área de $Y\left(A_{0} B_{0} B_{2} A_{1} A_{0}\right)$. Com respeito aos cálculos anteriores, para uma mudança paralela, $\overline{A_{0} A_{1}}$ é igual a $\left(K P_{0}\right)$. Assim,

$$
A_{0}=A_{1}+K P_{0}
$$

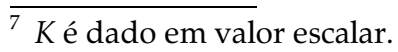


Substituindo a equação (9) na equação (7) tem-se a expressão (da parcela Y) do benefício social total (BST) para um deslocamento paralelo da curva de oferta. Somando-se esta equação a (8) obtém-se a expressão do BST:

$$
B S T_{\text {paralelo }}=X+Y=0,5 K P_{0}\left(Q_{1}+Q_{0}\right)
$$

No caso do deslocamento pivotal da curva de oferta:

$$
A_{0}=A_{1}
$$

Substituindo (11) na equação (7) e somando a esta a equação (8) obtém-se a expressão do BST para um deslocamento pivotal

$$
B S T_{\text {pivotal }}=X+Y=0,5 K P_{0} Q_{1}
$$

Seguindo Lindner e Jarret (1978) e Rose (1980) será obtido o ponto de equilíbrio $\left(B_{1}\right)$ após a intervenção governamental da seguinte maneira:

$$
\begin{aligned}
& P_{1}=P_{0}\left[1-\frac{K \varepsilon^{S}}{\varepsilon^{S}+\varepsilon^{D}}\right] \\
& Q_{1}=Q_{0}\left[1-\frac{K \varepsilon^{S} \varepsilon^{D}}{\varepsilon^{S}+\varepsilon^{D}}\right]
\end{aligned}
$$

Substituindo a equação (14) nas equações (10) e (12) e considerando que $\left(K \varepsilon^{S}\right) /\left(\varepsilon^{S}+\varepsilon^{D}\right)=W$, tem-se o BST para uma mudança paralela e pivotal da curva de oferta:

$$
\begin{aligned}
& B S T_{\text {paralelo }}=X+Y=0,5 K P_{0} Q_{0}\left(2+W \varepsilon^{D}\right) \\
& B S T_{\text {pivotal }}=X+Y=0,5 K P_{0} Q_{0}\left(1+W \varepsilon^{D}\right)
\end{aligned}
$$

Sendo:

$B S T=$ Benefício social total bruto, em R\$;

$K=$ Deslocador da curva de oferta e medidor da redução proporcional dos custos;

$P_{0}=$ Preço de equilíbrio de mercado no ano imediatamente anterior aos incentivos governamentais, em $\mathrm{R} \$ / \mathrm{kg}$;

$Q_{0}=$ Quantidade de equilíbrio de mercado no ano imediatamente anterior aos incentivos governamentais, em kg; 
$W=$ Relação entre o produto do deslocador da curva de oferta e a soma das elasticidades-preço da oferta e da demanda, em valor absoluto;

$\varepsilon^{D}=$ Elasticidade-preço da demanda de mamão, em valor absoluto;

$\varepsilon^{S}=$ Elasticidade-preço da oferta de mamão.

Como citam Abdallah e Bacha (1999), para a estimativa de K, é necessária uma estimativa da oferta de mamão antes e depois dos incentivos governamentais, respectivamente $O A_{\text {ex-ante }}$ e $O A_{\text {ex-post }}$, com respeito a $P_{0}$. A oferta assim considerada gera a quantidade $\mathrm{Q}_{2 \mathrm{t}} \mathrm{S}$ demonstrada na Figura 1.

Para se obter o benefício social total gerado pela política governamental, multiplicou-se o benefício social per capita obtido, pela população residente no estado do Ceará no ano de 2006.

\subsection{Modelo econométrico de equações simultâneas}

Neste estudo as funções de demanda e oferta são definidas, respectivamente, por:

$$
\begin{aligned}
& Q_{t}^{D}=f\left(P A_{t}, R D_{t}, P_{t}\right) \\
& Q_{t}^{S}=f\left(P M L_{t}, D_{t}, S M_{t}, P_{t}\right)
\end{aligned}
$$

Para atender aos objetivos de estimar as elasticidades, os modelos econométricos das funções (17) e (18) foram escritos na forma log-linear, para a qual o modelo é linear nos valores escalares dos parâmetros $\alpha_{0}, \alpha_{1}, \alpha_{2}, \alpha_{3}, \beta_{1}, \beta_{2}, \beta_{3}, \beta_{4}$ e da variável $D_{t}$, e linear nos logaritmos das variáveis $Q_{t}^{D}, P A_{t}, R D_{t}, P_{t}, Q_{t}^{S}, P M L_{t} S M_{t}$, respectivamente.

Equação de Demanda:

$$
\ln Q_{t}^{D}=\alpha_{0}+\alpha_{1} \ln P A_{t}+\alpha_{2} \ln R D_{t}+\alpha_{3} \ln P_{t}+\varepsilon_{t}
$$

Equação de Oferta:

$$
\ln Q_{t}^{S}=\ln \lambda_{0}+\beta_{1} \ln P M L_{t}+\beta_{2} \ln D_{t}+\beta_{3} \ln S M_{t}+\beta_{4} \ln P_{t}+v_{t}
$$

Logo, o Equilíbrio de Mercado:

$$
\ln Q_{t}^{D}=\ln Q_{t}^{S}
$$


Onde:

$\ln Q_{t}^{D}=$ Logaritmo natural da quantidade demandada "per capita" de mamão no mercado do Ceará (em tonelada), no ano $t$;

$\ln Q_{t}^{S}=$ Logaritmo natural da quantidade ofertada "per capita" de mamão no mercado do Ceará (em tonelada), no ano $t$;

$\ln P_{t}=$ Logaritmo da média ponderada corrigida dos preços dos diversos tipos de mamão no mercado cearense $(\mathrm{R} \$ / \mathrm{Kg})$, no ano $t$;

$\ln R D_{t}=$ Logaritmo natural da renda real "per capita" do estado do Ceará (R\$), no ano $t$;

$\ln \mathrm{PA}_{\mathrm{t}}=$ Logaritmo natural da média ponderada corrigida do preço do abacaxi no mercado cearense $(\mathrm{R} \$ / \mathrm{kg})$, no ano $t$;

$\ln P M L_{\mathrm{t}}=$ Logaritmo natural da média ponderada corrigida do preço do melão no mercado cearense $(\mathrm{R} \$ / \mathrm{kg})$, no ano $t$;

$D_{t}=$ Variável dummy, no ano $t$;

$D_{t}=0$ para os anos "ex ante" ao incentivo do governo à fruticultura do Ceará, $D_{t}=1$ para os anos "ex post" ao incentivo;

$\operatorname{lnSM} M_{t}=$ Logaritmo natural da média anual do salário mínimo Real $(R \$)$, no ano $t$;

$\varepsilon_{t}$ e $v_{t}=$ Termos de perturbação estocástica;

$\alpha_{0}, \alpha_{1}, \alpha_{2}, \alpha_{3}, \beta_{1}, \beta_{2}, \beta_{3}, \beta_{4}=$ Parâmetros a serem estimados.

Segundo as condições de ordem e de posto o modelo foi considerado completo e identificado, o processo para a estimativa do sistema e das equações estruturais é possível, podendo ser feito pelo Método dos Mínimos Quadrados de Dois Estágios.

Calculando-se a esperança matemática da equação estimada de oferta, obtém-se a equação da oferta per capita média condicional ${ }^{8}$ do mamão cearense $e x$ ante ao incentivo governamental, dada por:

$$
\begin{aligned}
& E\left(\ln \hat{Q}_{t}^{S} \mid \ln P M L_{t}, \ln S M_{t}, \ln \hat{P}_{t}, D_{t}=0\right)= \\
& =\hat{\beta}_{0}-\hat{\beta}_{1} \ln P M L_{t}-\hat{\beta}_{2} \ln S M_{t}+\hat{\beta}_{4} \ln \hat{P}_{t}
\end{aligned}
$$

Para o cálculo da média condicional da oferta per capita do mamão cearense ex post ao incentivo governamental foi utilizada:

$$
\begin{aligned}
& E\left(\ln \hat{Q}_{t}^{S} \mid \ln P M L_{t}, \ln S M_{t}, \ln \hat{P}_{t}, D_{t}=1\right)= \\
& =\hat{\beta}_{0}+\hat{\beta}_{3}-\hat{\beta}_{1} \ln P M L_{t}-\hat{\beta}_{2} \ln S M_{t}+\hat{\beta}_{4} \ln \hat{P}_{t}
\end{aligned}
$$

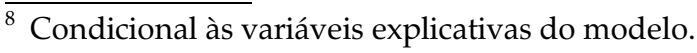




\section{Resultados e discussão}

\subsection{Análise da equação estimada de demanda de mamão para o estado do Ceará}

As variáveis explicativas utilizadas para estimar a equação de demanda per capita do mamão cearense $\left(Q_{t}^{D}\right)$ foram preço médio ponderado real do abacaxi $\left(P A_{t}\right)$, renda real per capita do estado $\left(R D_{t}\right)$ e o preço médio ponderado real estimado do mamão $\left(\hat{P}_{t}\right)$. Os resultados dos coeficientes estimados são apresentados na Tabela 1.

Tabela 1. Equação de demanda do mamão para o Ceará, de 1973 a 2006

\begin{tabular}{lcccc}
\hline \multicolumn{5}{c}{ Variável Dependente: $\ln \hat{Q}_{t}^{D}$} \\
\hline Variável & Coeficiente & Erro padrão & Estatística t & Valor de P. \\
\hline$\varphi_{0}$ & $-11,31087$ & 0,769134 & $-14,70599$ & 0,0000 \\
$\ln P A_{t}$ & 0,519704 & 0,151452 & 3,431475 & 0,0018 \\
$\ln R D_{t}$ & 3,171599 & 0,662593 & 4,786648 & 0,0000 \\
$\ln \hat{P}_{t}$ & $-1,901246$ & 0,277073 & $-6,861882$ & 0,0000 \\
\hline$R$ quadrado & 0,876385 & & & \\
R quadrado ajustado & 0,864024 & & & \\
Erro padrão da regressão & 0,528538 & & & \\
Estatística F & 70,89639 & Estatística Durbin-Watson & 1,161898 \\
Prob(Estatística F) & 0,000000 & & & \\
\hline
\end{tabular}

Fonte: Elaboração própria.

Dos resultados apresentados na Tabela 1, a partir do p-value, os coeficientes estimados das variáveis logaritmizadas, $\alpha_{1}$ do preço do abacaxi, $\alpha_{2}$ da renda e $\alpha_{3}$ do preço de mercado do mamão podem ser considerados estatisticamente diferentes de zero a um nível de significância de $1 \%$.

O sinal do coeficiente do logaritmo natural do preço do abacaxi é condizente com o previsto e indica que o abacaxi é uma fruta substituta do mamão, de modo que, quanto maior for $P A_{t}$, maior será a quantidade demandada de mamão $\left(Q_{t}^{D}\right)$. O valor desse coeficiente indica ainda que se o preço do abacaxi $P A_{t}$ aumentar em $10 \%$, a procura por mamão $\left(Q_{t}^{D}\right)$ aumentará, em média $5,19 \%$, ceteris paribus.

O sinal do coeficiente do logaritmo natural da renda corresponde ao esperado e indica o efeito positivo que esta exerce sobre a demanda do mamão, apontando que o mamão é um bem normal, uma vez que um incremento de $10 \%$ na renda per capita da população cearense expandirá em média 31,71\% a procura per capita de mamão, ceteris paribus.

O sinal negativo do logaritmo natural do preço do mamão confirma a hipótese da Lei Geral da Procura. Observa-se que a demanda per capita do mamão 
é elástica em relação ao seu preço, assim, uma redução de $10 \%$ no preço desta fruta induzirá um aumento médio de 19,01\% na quantidade demandada de mamão, ceteris paribus.

Com o valor do coeficiente de determinação ajustado verifica-se que $86,40 \%$ da variação média na quantidade do mamão é explicada pela variação conjunta das variáveis $P A_{t}, R D_{t}$ e $\hat{P}_{t}$ presentes no modelo. É necessário ressaltar que os testes apropriados mostraram que o modelo possui variância residual constante, ausência de multicolinearidade e sem evidência de presença de autocorrelação serial. ${ }^{9}$

\subsection{Análise da equação estimada de oferta de mamão no Ceará}

As variáveis explicativas utilizadas para estimar a equação de oferta per capita do mamão cearense $\left(Q_{t}^{S}\right)$ foram preço médio ponderado real do melão $\left(P M L_{t}\right)$, salário médio mínimo $\left(S M_{t}\right)$, preço médio ponderado real estimado do mamão ( $\left.\hat{P}_{t}\right)$, e a variável dummy $\left(D_{t}\right)$ para captar o efeito ex post aos incentivos do governo à fruticultura do estado do Ceará sobre o mercado do mamão, para a qual se tomou o ano 2001 como referência ao início do período pós-programas. Os resultados da equação estimada são apresentados na Tabela 2.

Tabela 2. Equação de oferta de mamão no estado do Ceará, de 1973 a 2006

\begin{tabular}{lcccc}
\hline \multicolumn{5}{c}{ Variável Dependente: $\ln \hat{\mathbf{Q}}_{t}^{S}$} \\
\hline Variável & Coeficiente & Erro padrão & Estatística t & Valor de P. \\
\hline$\lambda_{0}$ & 6,401721 & 3,583335 & 1,786526 & 0,0845 \\
$\ln P M_{t}$ & $-3,540927$ & 1,358253 & $-2,606971$ & 0,0143 \\
$\ln S M_{t}$ & $-1,769599$ & 0,714977 & $-2,475041$ & 0,0194 \\
$D_{t}$ & 3,903086 & 1,065684 & 3,662517 & 0,0010 \\
$\ln \hat{P}_{t}$ & 5,195809 & 2,602551 & 1,996429 & 0,0554 \\
\hline$R$ quadrado & 0,907101 & & & \\
$R$ quadrado ajustado & 0,894287 & & & \\
Erro padrão da regressão & 0,466023 & & & \\
Estatística F & 70,79184 & Estatística Durbin-Watson & 1,482183 \\
Prob(Estatística F) & 0,000000 & & & \\
\hline
\end{tabular}

Fonte: Elaboração própria.

${ }^{9}$ O teste para verificação de heterocedasticidade permitiu concluir pela ausência desta a um nível de significância de 5\% uma vez que a estatística. Obs*Square foi de 10,84 com p-value igual a 0,093. Problemas de multicolinearidade foram verificados por meio de matriz de correlação na qual não foi constatada nenhuma correlação significativa entre as variáveis. Por fim, a estatística Durbin-Watson igual a 1,1618 não permitiu concluir sobre a presença de autocorrelação. 
Na Tabela 2, comparando-se os valores absolutos dos $\beta^{\prime}$ s estimados e os respectivos erros-padrão, verifica-se que todos os coeficientes das variáveis podem ser considerados estatisticamente diferentes de zero, a um nível de significância de $1 \%$ (coeficiente de $\left.D_{t}\right), 5 \%$ (coeficientes de $\ln P M L_{t}, \ln S M_{t}$ ) e $10 \%$ (coeficiente de $\ln \hat{P}_{t}$ ).

O sinal negativo do coeficiente de $\ln P M L_{t}$ é consistente com o previsto. Indica que o melão é uma cultura competitiva em relação à do mamão em produção.

O coeficiente da variável logada salário mínimo possui o sinal negativo esperado e, portanto, a relação inversa entre quantidade ofertada de um produto e seu custo de produção.

O sinal positivo da variável dummy é coerente com o esperado e revela que a oferta do mamão sofreu um deslocamento para a direta (ou seja, um aumento) no período ex post à política de incentivo à fruticultura.

O coeficiente do logarítmo natural do preço do mamão tem o sinal positivo, confirmando a Teoria Econômica: quanto maior for o preço do mamão, maior será a quantidade ofertada desta fruta no mercado. A oferta per capita do mamão se revelou elástica, de modo que um aumento de $10 \%$ no preço da fruta provoca o incremento médio de 51,95\% na sua quantidade ofertada, ceteris paribus.

Observando o valor do Coeficiente de Determinação Ajustado verifica-se que $89,42 \%$ da variação média na quantidade ofertada do mamão é explicada pela variação conjunta das variáveis $P A_{t}, R D_{t}$ e $\hat{P}_{t}$ presentes no modelo.

Os resíduos na equação de oferta, da Tabela 2, possuem variâncias constantes e não têm evidência da presença de autocorrelação serial. ${ }^{10}$

\subsubsection{Ofertas estimadas para os períodos antes (1973/2000) e depois (2001/2006) da política de incentivos}

A média condicional da oferta per capita ex ante ao estímulo governamental, obtida a partir do modelo apresentado na Tabela 2 foi dada por:

$$
\begin{aligned}
& E\left(\ln \hat{Q}_{t}^{S} \mid \ln P M L_{t}, \ln S M_{t}, \ln \hat{P}_{t}, D_{t}=0\right)= \\
& =6,40-3,54 \ln P M L_{t}-1,77 \ln S M_{t}+5,20 \ln \hat{P}_{t}
\end{aligned}
$$

Extraídos os antilogs anuais, transformando a unidade de medida de tonelada para quilo e retirando-se a média aritmética dos 28 anos que definem o período de 1973 a 2000, foi possível obter o valor absoluto da média condicional da oferta per capita ex ant ao estímulo governamental:

$$
E\left(\ln \hat{Q}_{t}^{S} \mid \ln P M L_{t}, \ln S M_{t}, \ln \hat{P}_{t}, D_{t}=0\right)=1,16 K g
$$

\footnotetext{
${ }^{10} \mathrm{O}$ teste para verificação de heterocedasticidade permitiu concluir pela ausência desta a um nível de significância de 5\% uma vez que a estatística. Obs* Square foi de 9,27 com p-value igual a 0,233. A estatística Durbin-Watson igual a 1,4821 não permitiu concluir sobre a presença de autocorrelação.
} 
A média condicional da oferta per capita de mamão cearense ex post à intervenção governamental:

$$
\begin{aligned}
& E\left(\ln \hat{Q}_{t}^{S} \mid \ln P M L_{t}, \ln S M_{t}, \ln \hat{P}_{t}, D_{t}=1\right)= \\
& =6,40+3,54 \ln P M L_{t}-1,77 \ln S M_{t}+5,20 \ln \hat{P}_{t}+3,90 D_{t}
\end{aligned}
$$

Extraídos os antilogs anuais, transformando a unidade de medida de tonelada para quilo e retirando-se a média aritmética dos seis anos que definem o período de 2001 a 2006, foi possível obter o valor absoluto da média condicional da oferta per capita ex post ao estímulo governamental:

$$
E\left(\ln \hat{Q}_{t}^{S} \mid \ln P M L_{t}, \ln S M_{t}, \ln \hat{P}_{t}, D_{t}=1\right)=7,81 \mathrm{Kg}
$$

Analisando-se os termos do intercepto das equações de oferta per capita do mamão, estimada antes e após os incentivos à cultura, equações (24) e (26) respectivamente, observa-se que houve um deslocamento para a direita da curva de oferta per capita do mamão no período de 2001 a 2006. Isto pode ser comprovado pela variação de $573,28 \%$ nos valores médios da quantidade ofertada per capita condicional do mamão no Ceará. Isto revela uma ampliação da capacidade produtiva do estado.

A estimação dos preços anuais de equilíbrio de mamão no Ceará caiu nos anos consequentes ao incentivo do governo à fruticultura: diminuiu, em média, $\mathrm{R} \$ 0,65 / \mathrm{kg}$, indicando, portanto, um ganho para o consumidor.

\subsubsection{Estimativas da receita com a comercialização de mamão no Ceará}

As estimativas das receitas anuais per capitas e agregadas, obtidas pelos produtores com a comercialização do mamão encontram-se na Tabela 3. Pode-se notar um aumento de $\mathrm{R} \$ 1,82 / \mathrm{kg}$ na receita média per capita obtida pelo produtor com a comercialização do mamão no estado do Ceará após a implementação da política de incentivo à fruticultura. A receita média total gerada nos seis anos que delimitam o período pós-política supera em 384,66\% a média da receita auferida durante os 28 anos anteriores aos programas, o que confirma um aumento no excedente econômico para os produtores.

Tabela 3. Estimativas anuais das receitas dos produtores com a comercialização de mamão no Ceará, de 1973 a 2000 e de 2001 a 2006. (R\$/kg)

\begin{tabular}{lcc}
\hline Especificação & $\begin{array}{c}\text { Período "ex ante" } \\
(\mathbf{1 9 7 3} \text { a 2000) }\end{array}$ & $\begin{array}{c}\text { Período "ex post" } \\
\mathbf{( 2 0 0 1} \text { a 2006) }\end{array}$ \\
\hline Total agregado & $153.121 .339,17$ & $126.215 .122,61$ \\
Média agregada & $5.468 .619,26$ & $21.035 .853,77$ \\
Total per capita & 23,88 & 16,03 \\
Média per capita & 0,85 & 2,67 \\
\hline
\end{tabular}

Fonte: Elaboração própria. 


\subsection{Análise do benefício social dos incentivos governamentais concedidos aos produtores de mamão do estado do Ceará}

\subsubsection{Cálculo do benefício social total bruto}

A partir da função de oferta estimada por meio do modelo estimado (equação 25), calculou-se a quantidade ofertada de mamão ao nível $P_{0}$ para o ano de 2006, dada por $Q_{2(2006)}^{S}$. Considerou-se o preço fixo do ano de 2000 como $P_{0}$. Assim,

$\ln \hat{Q}_{2(2006)}^{S}=10,30-3,54 \ln P M L_{(2006)}-1,77 \ln S M_{(2006)}+3,90 D_{(2006)}+5,20 \ln \hat{P}_{(2006)}$

Extraído o antilog de $Q_{2(2006)}^{S}$, pôde-se calcular o valor escalar de $K$. De posse de $K$, do preço observado em $2000\left[P_{0(2000)}\right]$, da quantidade de oferta observada em $2000\left[Q_{0}(2000)\right]$ e das elasticidades-preço da demanda e da oferta - $\varepsilon^{D}$ e $\varepsilon^{S}$ respectivamente, obtiveram-se os valores de $P_{1}$ e $Q_{1}$ por meio das equações 13 e 14 .

Em seguida, calculou-se o benefício social per capita gerado no período de 2001 a 2006, de acordo com as equações 10 e 12.

A Tabela 4 fornece os valores de $Q_{2(2006)}^{S}, K, P_{1}, Q_{1}$ e os $B S_{\text {per capita }}$ e $B S_{\text {total }}$ para os deslocamentos paralelo e pivotal da curva de oferta de mamão a partir da política de incentivo à fruticultura cearense.

Tabela 4. Benefício Social Total (BST) estimado para o deslocamento paralelo e pivotal da curva de oferta de mamão, de 2001 para 2006

\begin{tabular}{|c|c|c|c|c|c|c|c|c|}
\hline \multirow{3}{*}{$Q_{2(2006)}^{S}$} & \multirow{3}{*}{$K$} & \multirow{3}{*}{$P_{1}$} & \multirow{3}{*}{$Q_{1}$} & \multirow{3}{*}{$\begin{array}{c}\text { População/CE } \\
2006\end{array}$} & \multicolumn{4}{|c|}{ Benefícios Sociais } \\
\hline & & & & & \multicolumn{2}{|c|}{ Deslocamento Padrão } & \multicolumn{2}{|c|}{ Deslocamento Pivotal } \\
\hline & & & & & $\begin{array}{c}\text { BS } \\
\text { per capita }\end{array}$ & $\begin{array}{l}\text { BS } \\
\text { Total }\end{array}$ & $\begin{array}{c}\text { BS } \\
\text { per capita }\end{array}$ & $\begin{array}{l}\text { BS } \\
\text { Total }\end{array}$ \\
\hline 21,04 & 0,153 & 0,37 & 6,8 & 8.176 .820 & 0,39 & $3.163 .045,86$ & 0,22 & $1.776 .805,12$ \\
\hline
\end{tabular}

Fonte: Resultados da pesquisa.

O benefício social gerado pela política de incentivo à fruticultura, considerada a partir do ano 2001 até 2006, totalizou um valor de R\$3.163.045,86 para um deslocamento paralelo da curva de oferta de mamão. Em termos per capita, o benefício foi de $\mathrm{R} \$ 0,39$. O deslocamento paralelo implica uma redução proporcional nos custos médios de produção da fruta no período ex post.

Considerando um deslocamento pivotal da curva, o benefício social é de R\$ $1.776 .805,12$, enquanto que o benefício por pessoa é de $\mathrm{R} \$ 0,22$. O deslocamento pivotal da curva de oferta de mamão implica que os custos médios se mantiveram constantes no período pós-incentivo. 
O benefício gerado a partir da ampliação da oferta e da respectiva queda nos custos médios de produção supera em 178,02\% o benefício para o qual a ampliação na oferta mantém esses custos inalterados.

\subsubsection{Benefício social por meio da geração de empregos na cultura do mamão}

Nos últimos seis anos, a média de empregos diretos gerados através da cultura de mamão no estado do Ceará é de 0,84homem/hectare/ano. A área plantada de mamão totalizou 1.517 hectares em 2006, gerando aproximadamente de 1.274 empregos diretos. A Tabela 5 apresenta o valor e o número de empregos diretos, indiretos e totais gerados pela atividade no período de 2001 a 2006.

Tabela 5. Número e valor de empregos gerados pela cultura do mamão no estado do Ceará no período de 2001 a 2006

\begin{tabular}{ccccccc}
\hline \multirow{2}{*}{ Ano } & \multicolumn{3}{c}{ Empregos $\left({ }^{*}\right)$ unidade } & \multicolumn{2}{c}{ Valor da Mão de Obra(**) R\$ } \\
\cline { 2 - 7 } & Diretos & Indiretos & Totais & Diretos & Indiretos & Totais \\
\hline 2001 & 1.386 & 2079 & 3.465 & $371.392,56$ & $557.088,84$ & $928.481,40$ \\
2002 & 1.515 & 2273 & 3.788 & $371.629,50$ & $557.444,25$ & $929.073,75$ \\
2003 & 718 & 1077 & 1.795 & $189.006,32$ & $283.509,48$ & $472.515,80$ \\
2004 & 848 & 1272 & 2.120 & $219.097,76$ & $328.646,64$ & $547.744,40$ \\
2005 & 1.023 & 1535 & 2.558 & $294.132,96$ & $441.199,44$ & $735.332,40$ \\
2006 & 1.273 & 1910 & 3.183 & $430.757,74$ & $646.136,61$ & $1.076 .894,35$ \\
TOTAIS & $\mathbf{6 . 7 6 3}$ & $\mathbf{1 0 . 1 4 5}$ & $\mathbf{1 6 . 9 0 8}$ & $\mathbf{1 . 8 7 6 . 0 1 6 , 8 4}$ & $\mathbf{2 . 8 1 4 . 0 2 5 , 2 6}$ & $\mathbf{4 . 6 9 0 . 0 4 2 , 1 0}$ \\
\hline
\end{tabular}

Fonte: ${ }^{(*)}$ informações fornecidas pela SEAGRI. ${ }^{* *}$ Elaboração própria.

OBS.: O numero de empregos indiretos é cerca de $150 \%$ o número de empregos diretos. O valor da mão de obra foi obtido através da multiplicação do número de empregos pelas médias anuais reais do salário mínimo vigente em cada período.

A partir dos dados da Tabela 5, verifica-se que, nos anos de 2003 e 2004, o número de empregos sofreu uma queda considerável. De acordo com Ximenes (2006), esta queda está associada a um ataque de pragas e à consequente redução da área cultivada da fruta. Atualmente, os técnicos da SDA juntamente com pesquisadores da Embrapa e técnicos da Seagri-Bahia estudam uma tecnologia específica como forma de conter a vulnerabilidade das plantações de mamão no estado.

Ao longo dos seis anos pós-política de incentivos, o valor da mão de obra somou R\$ 4.690.042,10, desse total, 40\% correspondem aos empregos diretos e, $60 \%$, aos empregos indiretos. 


\section{Conclusões e sugestões}

A partir dos objetivos de avaliação do benefício social gerado pelos incentivos governamentais aos produtores de mamão do Ceará propostos por este estudo, e com base nos resultados nele obtidos, foi possível concluir que, no estado, o mamãoé um bem normal e que sua demanda é elástica em relação ao seu preço. Verificou-se, também, que o consumo do abacaxi no estado é concorrente ao do mamão.

A quantidade ofertada de mamão no Ceará também tem uma elasticidade-preço alta, entretanto, mais sensível aos preços que a quantidade demandada da fruta. Por outro lado, em termos de produção, a cultura do melão caracterizou-se competitiva, sendo, portanto, uma alternativa aos produtores de mamão.

O comportamento dos preços apresentou-se descendente ao longo do tempo, sendo que em um maior grau no período ex post aos incentivos. Entretanto, observou-se que a queda nos preços não afetou de forma negativa a oferta per capita do mamão no estado como preza a Lei da Oferta. Aconteceu exatamente o inverso, houve um estímulo médio altamente substancial, da ordem de $573,27 \%$. Isto sugere que o aumento na oferta foi estimulado exogenamente por estratégias de investimento produtivo com indução de redução nos custos de produção do mamão.

A redução nos preços e o aumento na oferta do produto foram responsáveis por uma elevação no bem-estar social por meio de um aumento no excedente tanto do consumidor quanto do produtor.

O excedente econômico considerado a partir da redução nos custos médios anuais (deslocamento paralelo da oferta) superou em $78,02 \%$ o excedente econômico avaliado a partir de custos médios anuais constantes (deslocamento pivotal da oferta). Isto revela a importância de ações voltadas à redução nos custos de produção como forma de estimular o desenvolvimento da fruticultura no estado do Ceará.

A expressiva magnitude do benefício social resultante da intervenção governamental junto aos produtores revela a viabilidade desta fruta como fator de desenvolvimento econômico. Nesta nova condição de bem-estar social verifica-se que: (i) o aumento no excedente econômico do consumidor é consequência de um efeito preço, visto que, com os preços mais baixos, os consumidores passaram a demandar maiores quantidades de mamão; (ii) o aumento no excedente do produtor é resultante da significativa ampliação da oferta nos seis anos que delimitaram o período pós-incentivo. Adicionalmente, os mesmos perceberam um incremento em suas receitas médias "per capitas" de $167,05 \%$ e agregadas de $282,74 \%$ com a comercialização do mamão. 
Essa tendência corrobora com a crescente absorção de mão de obra no meio rural, gerando emprego e renda na região, o que tende afixar o agricultor no campo - problemas que, historicamente, se remetem em um expressivo entrave às políticas públicas voltadas a estas áreas.

Em razão do que foi exposto até então, conclui-se que os incentivos governamentais do estado do Ceará, com os seus diversos programas de fomento ao segmento econômico da fruticultura, considerados aqui para o período de 2001 a 2006, projetaram a cultura do mamão, gerando uma tendência de ampliação da produção e oferta desta fruta, além de promoverem um aumento no bem estar da sociedade cearense.

Considerando a importante representatividade econômica que a produção já existente de mamão tem para o estado e a viabilidade desta cultura em termos de geração de emprego e renda, da crescente procura do mercado consumidor nacional e internacional, além do grande número de produtores, é necessário implementar ações mais específicas para o incremento de tecnologia, controle de pragas e doenças, além do estímulo à produção e à produtividade.

Sugere-se a criação de mecanismos públicos, sistemáticos, amplos e eficientes de informações históricas a respeito das categorias e montantes dos investimentos concedidos pelo governo do Ceará aos produtores de mamão. Isto, além de estimular a pesquisa científica no estado, viabilizaria uma análise classificada de benefício-custo social gerado pelos incentivos governamentais a este setor da economia.

\section{Referências Bibliográficas}

ABDALLAH, P. R. e BACHA, C. J. C. Análise Benefício/Custo da Política Brasileira de Incentivo Fiscal à Pesca. Revista de Economia e Sociologia Rural. Vol37. n. 3. 1999.

AYER, H. W.; SCHUH, G. E. Social rates of return and other aspectos of agricultural research: the case of cotton research in São Paulo, Brazil. American Journal of Agricultural Economics, v.56, n.1, p.175-179, 1974.

AKINO, M. \& HAYAMI, Y. Efficiency and equity in public research: rice breeding in japan's economic development. American Journal of Agricultural Economics, v.57, n.1, p.1-10, 1975.

BACHA, C.J.C. Análise custo-benefício dos programas federais de incentivo ao reflorestamento no Brasil. Piracicaba: ESALQ/USP/CNPq, 1995. 93p. (Relatório de pesquisa).

BARRETO, P. D. et. al.. Inter-relações entre variáveis associadas à precocidade, ao crescimento e ao teor de nutrientes absorvidos de mamoeiro. EMBRAPA: Boletim de Pesquisa e Desenvolvimento 7. Dez. 2002. Fortaleza. 24p. 
EMBRAPA. EMPRESA BRASILEIRA DE PESQUISA AGROPECUÁRIA. Produção integrada do melão: sistema de produção. Disponível em: http://www.cnpa.embrapa.br/frutas/cap.2.pdf. Acesso em: 10 de out. de 2006.

FERREIRA, M. M. Retorno aos investimentos em pesquisa e assistência técnica na cultura do café em Minas Gerais. Viçosa, 1993. Dissetação (Master Science) Universidade Federal de Viçosa.

FONSECA, M. A. A. S. Retorno social aos investimentos em pesquisa na cultura do café. Piracicaba, 1976. 148p. Dissertação (Máster Science) - Escola superior de Agricultura "Luiz de Queiroz", Universidade de São Paulo.

GRILICHES, Z. Research cost and social returns: hybrid corn and related innovations. Journal of Political Economy, v.66, n.1, p.9-31, 1958.

HAYAMI, Y. \& HERDT, R. W. Market price effects of technological change on income distribution in semisubsistence agriculture. American Journal of Agricultural Economics, v.59, n.5, p.245-256, 1977.

HERTFORD, R. \& SCHMITZ, A. Measuring economic returns of agricultural research. Resource Allocation and Productivity in National and International Agricultural Research. Minneapolis, University of Minnesota Press, 1977. p. 148-167.

IPEADATA - INSTITUTO DE PESQUISA ECONÔMICA APLICADA. Indicadores econômicos. Disponível em http://.ipeadata.gov.br-Acesso em: 05 de mar de 2006.

IPECE - INSTITUTODE PESQUISA E ESTRATÉGIA ECONÔMICA DO CEARÁ. Ceara em números 2004. Fortaleza, v. 17, p. 1-165, 2004.

KHAN, A.S. e SOUZA, J. S. Taxa de retorno social do investimento em pesquisas na cultura da mandioca no Nordeste. Revista de Economia e Sociologia Rural. Brasília, 29 (4) : 411-426, 1991.

LINDNER, R. K. \& JARRET, F. G. Supply Shift And The Size Off Research Benefit. American Journal Of Agricultural Economics. v.60, n.1, p. 48-58, 1978.

MONTEIRO, A. Avaliação econômica da pesquisa e extensão agrícola: o caso do cacau no Brasil. Viçosa, 1975. 75p. Dissertação (Master Science) - Universidade Federal de Viçosa.

PETERSON, W. L. Return to poultry research in the United States. Journal of Farm Economics, v.49, n.8, p.656-661, 1967.

ROSE, F. Suppley Shifts and The Size Off Research Benefits: Comment. American Journal Off Agricultural Economics, v. 62, n. 4, 1980, p. 834-837. 
SANTANA, A. C. Avaliação e distribuição dos retornos sociais da adoção tecnológica na cultura do feijão caupi no Nordeste. Fortaleza, 1987. 59p.Dissertação (Máster Science) - Universidade Federal do Ceará.

SANTANA, A. C. de e KHAN A. S. Custo social da depredação florestal no Pará: o caso da castanha-do-brasil. Revista de Economia e Sociologia Rural. Brasília, v. 30, no 3, jul./set. 1992, p. 253-269.

SCHMITZ, A. e SECKLER, D. Mecanized agriculture and social welfare: the case of the tomato harvester. American Journal of Agricultural Economics, v.52, n.11, p.569-577, 1970.

SDE - SECRETÁRIA DE DESENVOLVIMENTO ECONÔMICO DO CEARÁ. Política de desenvolvimento econômico do Ceará. Fortaleza, 2004.72 p. Disponível em: http://www.sde.ce.gov.br. Acesso em 04 de jun. de 2006.

SEAGRI - SECRETARIA DA AGRICULTURA E PECUÁRIA DO CEARÁ. SIGA Sistema de Informação Gerencial Agrícola. I.Projeto Frutas do Ceará. Fortaleza, 2006 Disponível em www.seagri.ce.gov.br Baixado em 30 de nov de 2006.

SDR - SECRETARIA DE DESENVOLVIMENTO RURAL. Rumo ao desenvolvimento rural do Ceará - 1999/2002. 1999. Fortaleza 97 p.

SILVA, A. S. e KHAN A. S.. Benefícios sociais da substituição de milho por raspa de mandioca em ração suína no Estado do Ceará. Revista de Economia e Socióloga Rural, v. 32, no 1, jan./mar. 1994, p. 87-98. 